\title{
Adenoma detection rate evaluation and quality of colonoscopy in the Center-West Region of Brazil
}

\author{
Daniela Medeiros Milhomem CARDOS0 ${ }^{1,2,3}$, Marco Aurélio Silveira BOTACIN² and Marilia Adriano MEKDESSI²
}

Received 4/6/2017

Accepted 29/8/2017

\begin{abstract}
Background - Colorectal cancer is the third commonest cancer in men and the second in women worldwide. Peculiarities of its evolution allow secondary prevention measures through colonoscopy, with high diagnostic and therapeutic capacity. In this context, the quality indicators of the procedure become important, among them the adenoma detection rate (ADR). Objective - To relate the ADR in a medium risk population subjected to colonoscopy with sociodemographic, technical and histopathological indicators. Methods - This was a descriptive, observational and retrospective study whose data were collected from medical records of colonoscopy exams with the indication of colorectal cancer screening or prevention in the period from August to October 2016. Results - A total of 436 exams were included for analysis. Female sex represented $66.3 \%$ with 289 patients versus $33.7 \%$ for men. Patients aged between 50 and 59 years were $223(51.1 \%)$ and those between 60 and 75 years were 213 (48.9\%). In 99 exams (22.7\%) chromoscopy was used, and 420 patients $(96.3 \%)$ were adequately prepared. There were 118 patients with adenomas, resulting in an overall ADR of $27.1 \%$. The ADR for men was $30.6 \%$ and $25.3 \%$ for women. Patients between 60 and 75 years old had a significantly higher ADR (31.9\%, compared to $22.4 \%$ of the younger ones). Examinations in which chromoscopy was used also presented higher ADR. Conclusion - The ADR values found for the population of the studied region were compatible with internationally established goals. Continuous evaluation of the ADR may yield interventions aimed at improving quality standards for colonoscopy and promote better prevention of colorectal cancer.
\end{abstract}

HEADINGS - Adenoma. Colorectal cancer. Colonoscopy.

\section{INTRODUCTION}

Globally, colorectal cancer (CRC) is the third commonest cancer in men, and the second commonest in women. In the United States of America, it is the fourth commonest type of cancer and the second leading cause of cancer-related mortality ${ }^{(9,13)}$.

In Brazil, according to 2016 estimates by the National Cancer Institute (INCA), $\mathrm{CRC}$ was the third most prevalent cancer among men and the second among women. Its incidence also varied according to the region evaluated. In men, it was the second most frequent in the Southeast Region (24.27/100,000 population), third most frequent in the South (22.35/100,000 population) and Central West (14.16/100,000 population) Regions, and the fourth most frequent in the Northeast (7.05/100,000 population) and North (5.34/100,000 population) Regions. Among women, it was the second most frequent in the Southeast (22.66/100,000 population) and South (23.27/100,000 population) Regions, and the third most frequent in the Central-West Region (16.93/100,000 population), Northeast $(8.77 / 100,000$ population) and North $(5.89 / 100,000$ population) Regions ${ }^{(16)}$.

The natural history of CRC provides opportunities for effective secondary prevention, as it is proven that there is a process to the development of CRC. Alteration of the colonic mucosa occurs in the following sequence: hyperplasia, adenoma, and carcinoma ${ }^{(11)}$. It is known that $90 \%$ of CRC cases arise from an adenoma and that it takes about 10 years for a polyp greater than $1 \mathrm{~cm}$ in size to become an invasive malignancy ${ }^{(30)}$. As noted by several authors, this allows time for early preventive measures to detect cancer precursors, with high cure rates and provides proven benefits in reducing mortality from colorectal cancer ${ }^{(9,11,13)}$.

Colon and rectal cancer survival depend largely on the disease stage. Generally, the earlier the disease is diagnosed, the longer the survival. The 5-year survival rate for patients with early disease (limited to the intestinal mucosa) is $90 \%$, that for regional disease (with lymph node involvement) is $68 \%$, and that for metastatic disease is only $10^{\%} \%^{(24,28)}$.

Taking into account that the initial lesions are asymptomatic and that the risk of CRC is rare before age 50 and increases with age, screening is recommended for the asymptomatic population aged 50 years and above $\mathrm{e}^{(9)}$. Several tests are used to screen for CRC: barium enema, fecal occult blood test, rigid and flexible rectosigmoidoscopy, and colonoscopy. Among them, colonoscopy stands out because of its high sensitivity; it allows complete visualization of the colonic mucosa, facilitating the detection and removal of polyps, and biopsies for cancer screening ${ }^{(9)}$.

According to the 1993 United States National Polyp Study, colonoscopic polypectomy reduced the incidence of CRC by 76 to 90 percent $^{(23)}$. Since 1997, the American Gastroenterological Association has recommended screening for all asymptomatic individuals, aged 50 or older, with no family history of CRC. These individuals are in the medium-risk group ${ }^{(9)}$.

Despite its obvious advantages, colonoscopy has its limitations:

Declared conflict of interest of all authors: none

Disclosure of funding: no funding received

${ }^{1}$ Divisão de Endoscopia Digestiva, Hospital das Clínicas, Universidade Federal de Goiás, Goiânia, GO, Brasil; ${ }^{2}$ PuC Goiás, Goiânia, GO, Brasil; ${ }^{3}$ Instituto do Aparelho Digestivo, Goiânia, GO, Brasil. Correspondence: Dr. Daniela Medeiros Milhomem Cardoso. Rua 52 esquina com rua 66, número 92, ap. 901-S Ed Grann Parc. Jardim Goiás - CEP 74810-200 - Goiânia, GO, Brasil. E-mail: danielammcardoso@gmail.com 
adequacy of intestinal preparation, risks related to sedation, the risk of perforation, the risk of missing neoplasia, and high $\operatorname{cost}^{(23)}$. For lesions smaller than $10 \mathrm{~mm}$, the "miss rates" can reach $11 \%$ and the rate of inadequate colon preparation reaches $25 \%{ }^{(5)}$. This can lead to an avoidable increase in the number of examinations, affecting the cost-benefit ratio. Also, examinations performed under inadequate intestinal preparation are associated with elevated interval cancer rates (cancers diagnosed at screening intervals) ${ }^{(5)}$.

Quality indicators gained attention after the publication of a study by the US Institute of Medicine on medical errors in 2000 . In that study, it was reported that 44,000 to 98,000 Americans died each year due to medical errors ${ }^{(2)}$. This refers to measurable items related to the medical care process that reflect the quality of service provided to society. Once specific quality goals are established, it is necessary to determine desired outcomes to monitor and evaluate the proposed goals.

Reduction of CRC incidence and mortality is the most relevant and important outcome for those who perform colonoscopy; thus, evaluation of this goal is essential ${ }^{(4)}$. Risk of interval cancer is another outcome parameter. A high-quality colonoscopy decreases the chance of missing or misdiagnosing existing lesions, and recommendations for screening are made under these assumptions ${ }^{(21)}$.

Since 2002, quality indicators for colonoscopy have been published ${ }^{(26,27)}$. The joint task force of the American Society for Gastrointestinal Endoscopy (ASGE) and the American College of Gastroenterology on "Quality Indicators for Colonoscopy" proposed a 14 goal consensus on quality indicators. Only two of these goals have strong degrees of recommendation -1) appropriate indication for and frequency of use of recommended post-polypectomy colonoscopy and 2) post-resection cancer screening intervals. Intermediate recommendation grades exist for cecal intubation, adenoma detection rate (ADR), biopsy of inflammatory bowel disease, and post-polypectomy endoscopic management of bleeding. Currently, ADR has been gaining more and more international recognition as a quality indicator ${ }^{(27)}$. ADR is the only factor that correlates with the diagnosis of interval cancer; a higher ADR is associated with a lower incidence of interval cancer.

The ADR is the percentage of colorectal adenomas histologically proven by screening colonoscopies performed by a physician or a service. Currently, ASGE recommends an ADR of $20 \%$ or more for female patients and $30 \%$ for male patients ${ }^{(27)}$; however, there is a lack of data regarding the validation of this goal.

Several factors are associated with an increase in ADR, such as the use of chromoscopy, withdrawal time, quality of intestinal preparation, and the use of antispasmodic drugs ${ }^{(27)}$. However, studies about factors that may interfere with the rate are not unanimous, which makes it difficult to reach a consensus.

The variation in ADR has been widely described. A metaanalysis showed a large variation in this rate (8.8\% to $50 \%)$ among US primary care physicians ${ }^{(7)}$. A systematic review suggested that a significant improvement in ADR occurred only in relation to patient factors such as age and gender, as well as the quality of intestinal preparation $^{(33)}$. The set reference values for ADR, therefore, depend on the details of each country's screening programs, such as the age and sex of the selected individuals ${ }^{(26)}$.

There is no consensus regarding the ideal value of ADR, and this may vary according to the geographic location. In Brazil and specifically in the Center-West Region there is a lack of data on this quality parameter. Thus, this present study sought to obtain data to establish goals and parameters of ADR in Brazil, as well as the sociodemographic, technical and histopathological indicators of a higher ADR.

\section{METHODS}

This is an observational, retrospective study. Data were collected from the clinic, and medical records of patients admitted to the IAD (Instituto do Aparelho Digestivo de Goiânia - GO) from August 2016 to October 2016.

Patients who received a colonoscopy with indications for CRC screening or prevention were included in this study. Exclusion criteria were patients: 1) younger than 50 and above 75 years, 2) with a previous personal history of CRC or other neoplasia, 3) at high risk for CRC (intestinal polyposis syndrome, inflammatory bowel disease, non-polypoid colorectal cancer syndrome or a first degree relative with $\mathrm{CRC}$ ), 4) who were symptomatic (those in whom the colonoscopy was performed for lower-intestinal bleeding, altered bowel habits, weight loss, or anemia), 5) with a history of colorectal resection for indications other than $\mathrm{CRC}, 6$ ) with an incomplete colonoscopy (for technical reasons or due to inadequate intestinal preparation), and 7) whose clinical data could not be retrieved from the medical records.

The present study was evaluated and approved by the Ethics and Research Committee (ERC) of Goiânia General Hospital under the registration number CAEE 62503816.9.0000.0035. Data collection began after approval by the ERC.

All the included examinations were performed by seven endoscopists accredited by the Brazilian Society of Digestive Endoscopy (SOBED) and performed with the Olympus GIF CV-145, CV-150, and Q-180 gastroscopes.

Data collection from patients' charts was initiated after obtaining a Free and Informed Consent Term authorizing access to the information contained in the patients' records.

Data were collected from patients undergoing colonoscopy with the indication of prevention and/or screening. Data collection was conducted using a form, prepared by the authors of the project. The form assessed the following variables: sociodemographic data, indications for colonoscopy, information regarding the quality of intestinal preparation, the findings of the colonoscopy examination, and the histopathological results. The data collection was conducted using the information available in the image capture program Laudo e Cia version 1.9.6 ${ }^{\circledR}$.

In order to standardize the data collected, a definition of terms was needed. Polyp was defined as a tissue structure that projects above the mucosal surface of the digestive tract, in a regular and circumscribed manner. It may appear as a flat or slightly raised lesion, sessile, subpediculated, or pedunculated, according to its implantation in the mucosa, and can be classified histologically as neoplastic or non-neoplastic. Adenomatous polyps are divided into tubular, tubulovillous and villous, with varying degrees of intraepithelial dysplasia; some may present as malignancies at the time of diagnosis ${ }^{(8)}$. There are also serrated polyps of hyperplastic lineage, which are characterized by a serrated, fenestrated, or dentate appearance of the epithelial crypts and may have dysplastic elements $^{(29)}$

The sociodemographic variables analyzed in the study were age and sex. Regarding age, the patients were stratified into 2 age groups: 50 to 59 years of age and 60 to 75 years of age.

All patients enrolled in the study underwent preparation with three tablets of bisacodyl the day before the examination, together with $500 \mathrm{~mL}$ of $20 \%$ mannitol diluted in $500 \mathrm{~mL}$ of liquid on the day of the examination. The quality of intestinal preparation was evaluated using the standardized Boston Bowel Preparation Scale. For the analyses of the preparations, at the discretion of the researchers, scores greater than or equal to 6 on the Boston scale 
were considered satisfactory ${ }^{(20)}$. Patients were also categorized based on the use or otherwise of chromoscopy.

Regarding localization, the left colon contains polyps located in the rectum, sigmoid colon and descending colon, whereas the right colon contains polyps located in the cecum, transverse colon, and ascending colon. The adenomas were histologically classified as tubular, tubulovillous, villous, and serrated. Dysplasia was graded as low or high grade, and the adenomas were separated into regions following the same criteria used for polyps.

Patients' variables were collected and compiled in a database with the program Microsoft Excel ${ }^{\circledR}$ for Windows and Microsoft Excel $^{\circledR}$ for Macintosh 2011 version 14.4.3, and were analyzed using the Statistical Package for the Social Sciences $\left(\mathrm{SPSS}^{\circledR}\right)$ for Windows version 18.0 and OpenEpi version 3.02.

Quantitative variables were analyzed based on variability measured as means and standard deviations. Categorical variables were analyzed according to frequencies. The association between the variables was made using the chi-square test and a value of $P<0.05$ was considered statistically significant.

\section{RESULTS}

A total of 450 colonoscopy examinations were performed from August to October 2016 with indications for screening or prevention. Nine examinations were excluded due to technical difficulties that prevented their completion, three because of history of previous intestinal surgery, and two that lacked biopsy results. Thus, 436 examination reports were included for data analysis.

There was a predominance of female patients among the patients examined $(289 / 436,66.3 \%)$; the number of men was $147(33.7 \%)$. The mean age was 60.09 years (standard deviation \pm 6.75 ). For the analysis, we subdivided the patients into two age groups: 223 patients aged 50-59 (51.1\%), and 213 patients aged $60-75$ years $(48.9 \%)$.

Regarding the technical aspects of colonoscopy, in 99 examinations $(22.7 \%)$, chromoscopy was used to assist in the visualization of the colon. It was established that adequate preparations would be those with values greater than or equal to 6 on the Boston Scale. In the sample, 420 test preparations $(96.3 \%)$ were considered adequate (Table 1 ).

TABLE 1. Demographic data and technical aspects of the colonoscopies carried out

\begin{tabular}{lccc}
\hline & & N & $\%$ \\
\hline Sex & Female & 289 & 66.3 \\
\multirow{3}{*}{ Age group } & Male & 147 & 33.7 \\
\multirow{3}{*}{ Chromoscopy } & $50-59$ & 223 & 51.1 \\
\multirow{3}{*}{ Preparation } & $60-65$ & 213 & 48.9 \\
& Yes & 99 & 22.7 \\
& No & 337 & 77.3 \\
& Adequate & 420 & 96.3 \\
\hline
\end{tabular}

The cecal intubation rate was $100 \%$. Due to the retrospective nature of the study, it was not possible to collect data on the time of colonoscope withdrawal; thus, this variable was excluded from the proposed analysis.

One hundred and fifty-three patients with polyps were identified among the 436 patients subjected to colonoscopies $(35.1 \%)$.
Regarding the distribution of polyps in the colon, 74 patients presented polyps in the right colon (17\%), 116 in the left $(26.6 \%)$, and 36 presented polyps in both the right and left colon. In total, 65 patients had more than one polyp $(42.5 \%)$. The total number of polyps diagnosed during colonoscopies was 318, divided into 125 polyps in the right colon and 193 in the left colon. A CRC compatible lesion was also found. Regarding the anatomopathological examinations, 118 patients had one or more adenomas, with an overall ADR of $27.1 \%$.

Regarding the distribution in the colon segments, 69 patients had adenoma in the right colon and 89 in the left, and 34 presented with adenomas in both segments. Thirty-nine patients had more than one adenoma (33.1\%). Figure 1 shows the location of the adenomas diagnosed according to the segments of the colon.

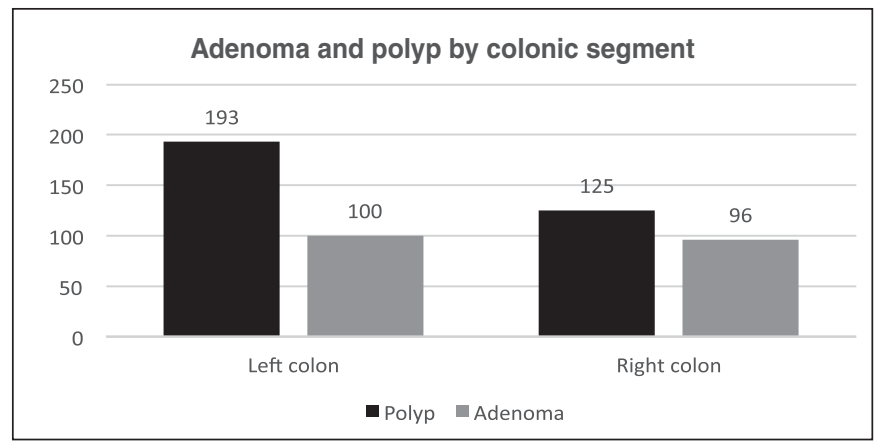

FIGURE 1. Distribution of adenomas and polyps by colonic segment.

Among the adenomas, there were 144 tubular adenomas with low-grade dysplasia, 4 tubular adenomas with high-grade dysplasia, 32 serrated adenomas with low-grade dysplasia, 10 tubulovillous adenomas with low-grade dysplasia, and 6 tubulovillous adenomas with high-grade dysplasia (Table 2 ). An adenocarcinoma was also found in the sample.

TABLE 2. Frequency of histopathological findings compatible with adenoma

\begin{tabular}{lcc}
\hline Histological classification of adenomas & N & $\%$ \\
\hline Tubular with LGD & 144 & 73.4 \\
Tubular with HGD & 4 & 2.0 \\
Tubulovillous with LGD & 10 & 5.0 \\
Tubulovillous with HGD & 6 & 3.3 \\
Serrated with LGD & 32 & 16.3 \\
\hline LGD: low-grade dysplasia; HGD: high-grade dysplasia. & &
\end{tabular}

Among the evaluated samples, 45 men had at least one adenoma, resulting in a male ADR of $30.6 \%$. Seventy-three women had at least one adenoma, with an ADR of $25.3 \%$. Although the data pointed to a higher ADR in men, this difference was not statistically significant (Table 3).

TABLE 3. Distribution of diagnosed adenomas in relation to sex

\begin{tabular}{lccc}
\hline Adenoma & Female $(\%)$ & Male $(\%)$ & Total $(\%)$ \\
\hline Yes & $73(25.3)$ & $45(30.6)$ & $118(27.1)$ \\
No & $216(74.7)$ & $102(69.4)$ & $318(72.9)$ \\
Total & $289(66.3)$ & $147(33.7)$ & $436(100)$ \\
\hline$P=0.283$. OR: $1.30(95 \%$ CI: $0.84-2.02)$ & &
\end{tabular}


The distribution of adenomas in the colon segments did not show statistically significant changes when analyzed in relation to the patient's sex. The stratification of patients according to age groups revealed an association with ADR. For the youngest stratum (between 50 and 59 years of age) the ADR found was $22.4 \%$, whereas, for the older patients (ages between 60 and 75 years), it was $31.9 \%$ (Table 4). Patients in the younger age stratum also had a higher rate of adequate colon preparation compared to patients in the older age group $(99.5 \%$ of the youngest patients versus $93 \%$ of the older patients) (Table 5). Nonetheless, the ADR was not associated with better or worse preparation quality.

TABLE 4. Distribution of diagnosed adenomas according to age groups

\begin{tabular}{lccc}
\hline & \multicolumn{3}{c}{ Age groups (years) } \\
\hline Adenoma & $50-59(\%)$ & $60-75(\%)$ & Total $(\%)$ \\
Yes & $50(22.4)$ & $68(31.9)$ & $118(27.1)$ \\
No & $173(77.6)$ & $145(68.1)$ & $318(72.9)$ \\
Total & $223(51.1)$ & $213(48.9)$ & $436(100)$ \\
\hline
\end{tabular}

$P=0.03$. OR: 1.62 (95\% CI: $1.05-2.48$ ).

TABLE 5. Distribution of the patients' age groups according to the quality of colon preparation

\begin{tabular}{lccc}
\hline $\begin{array}{l}\text { Age group } \\
\text { (years) }\end{array}$ & $\begin{array}{c}\text { Adequate } \\
\text { preparation }(\%)\end{array}$ & $\begin{array}{c}\text { Inadequate } \\
\text { preparation }(\%)\end{array}$ & Total $(\%)$ \\
\hline $50-59$ & $222(99.5)$ & $1(0.5)$ & $223(51.1)$ \\
$60-75$ & $198(93.0)$ & $15(7.0)$ & $213(48.9)$ \\
Total & $420(96.3)$ & $16(3.7)$ & $436(100)$ \\
\hline
\end{tabular}

$P=0.001$. OD: 16.81 (95\% CI: 2.20-128.47).

Another positive association was observed between the use of chromoscopy and the ADR (Table 6). The association of the use of chromoscopy with the different age groups, however, was not significant. Serrated adenomas were histologically diagnosed in 23 patients. The diagnosis of these lesions had a strong association with the use of chromoscopy (Table 7). There was no association between sex and age, suggesting that the sex distribution by age was similar. The sex variable was also not associated with the quality of the preparation.

TABLE 6. Relationship between adenomas diagnosed and the use of chromoscopy

\begin{tabular}{lccc}
\hline \multicolumn{3}{c}{ Chromoscopy } \\
\hline Adenoma & Yes $(\%)$ & No $(\%)$ & Total $(\%)$ \\
No & $31(31.3)$ & $287(85.2)$ & $318(72.9)$ \\
Yes & $68(68.7)$ & $50(14.8)$ & $118(27.1)$ \\
Total & $99(22.7)$ & $337(77.3)$ & $436(100)$ \\
\hline
\end{tabular}

$P<0.0001$. OD 0.07 (95\% CI: 0.04-0.13).

TABLE 7. Relationship between the number of patients diagnosed with serrated adenoma and the use of chromoscopy

\begin{tabular}{lccc}
\hline $\begin{array}{l}\text { Serrated } \\
\text { adenoma }\end{array}$ & Yes $(\%)$ & $\begin{array}{c}\text { Chromoscopy } \\
\text { No }(\%)\end{array}$ & Total $(\%)$ \\
\hline Yes & $14(14.1)$ & $9(26.7)$ & $23(5.3)$ \\
No & $85(85.9)$ & $328(73.3)$ & $413(94.7)$ \\
Total & $99(22.7)$ & $337(77.3)$ & $436(100)$ \\
\hline
\end{tabular}

$P<0.0001$. OD: 6.00 (95\% CI: 2.51-14.33).

\section{DISCUSSION}

This study is the first in our region to evaluate quality indicators, most notably the ADR in colonoscopies performed with the objective of colorectal cancer screening. The findings in the study sample revealed a general ADR in the clinic of $27.1 \%$, an ADR of $25.3 \%$ in women and $30.6 \%$ in men. Significant associations were observed between ADR and age groups, with higher rates among the elderly, who, in turn, had less adequate colon preparations. The colonoscopies performed at the clinic met quality parameters proposed by the endoscopy societies. The study had a high rate of adequate preparation $(96 \%)$ and cecal intubation $(100 \%)$.

Effective colonoscopy depends on both patient-related and endoscopist-related factors. Setting quality standards in colonoscopy is a priority sought by numerous endoscopic specialty societies, health management agencies, and governments, especially those with well-established colorectal cancer screening programs $^{(27)}$.

Quality standards or indicators can be structural, involving improvement in the health system, or process, such as improving ADR. The ultimate goal of establishing quality goals and standards is to reduce the mortality and incidence of colorectal cancer, and more recently, to reduce rates of interval cancer ${ }^{(27)}$.

Among the many quality indicators described in colonoscopy, the rate of adequate colon preparation stands out. An inadequate colon preparation, in addition to preventing the identification of subtle lesions of less than $5 \mathrm{~mm}$ in size, may also increase the time spent in performing the procedure, compromise the execution and the arrival of the device to the cecum, and increase the risk of intercurrences. The recommended value, according to ASGE, is higher than $90 \%{ }^{(27)}$. In the present study, it was observed that $96.1 \%$ of the patients were adequately prepared for the examination.

This high percentage of preparation increases the reliability of the findings in the present study. Colonoscopies performed with inadequate preparation directly affect ADR and the risk of interval cancer. The patient with inadequate preparation should repeat the examination early, usually within 1 year, negatively affecting the cost-effectiveness of colonoscopy ${ }^{(27)}$.

There was an association of inadequate preparation in the older age population (between 60 and 75 years of age). Age is considered an independent risk factor for poor intestinal preparation ${ }^{(19)}$. This may occur due to slowed bowel motility, previous surgeries and other comorbidities, a high rate of constipation, poor adherence, and misunderstanding of the preparation instructions. Some authors recommend that older patients undergo pre-procedure consultations for evaluation, and that an individualized approach is used to improve preparation rates ${ }^{(6)}$.

Another parameter recommended by ASGE as a quality criterion is a cecal intubation rate greater than 95 ; in the study population, the rate found was $100 \%$. A high rate of cecal intubation is a goal that should be pursued because of the high prevalence of adenomas in the right colon, which imposes this parameter ${ }^{(27)}$. There is great speculation in the literature regarding right colon lesions. Numerous authors have suggested that colonoscopy fails to prevent cancer in this location. There are speculations that the tumorigenesis of these lesions is distinct from those of the left colon. There is a higher rate of serrated lesions and flat laterally spreading tumors, which are more difficult to identify macroscopically. In addition, there is great interference with the quality of the preparation and technical aspects of the procedure. In this way, seeking high rates of cecal intubation allows the diagnosis of lesions considered "difficult" which leads to a reduction in the percentage of undiagnosed lesions ${ }^{(27)}$. 
One of the most important quality criteria in colonoscopy is the ADR, which correlates inversely with the incidence of interval cancer; the overall ADR in the study population was $27.1 \%$. The current target of the overall rate under the ASGE guidelines is $25 \% \%^{(27)}$. When assessed by sex, the observed ADR was $25.3 \%$ for female patients and $30.6 \%$ for male patients. These values are in agreement with the rates recommended by the North American and European colonoscopy quality consensuses. These societies establish ADRs of at least $20 \%$ and $30 \%$ for women and men, respectively ${ }^{(26,27)}$. The findings of the present study can validate the applicability of these global targets in the Center-West Region of Brazil.

Corley et al. evaluated the ADR and the percentage of interval cancer in a population. They identified rates ranging from $7.4 \%$ to $52.5 \%$ and found an inverse relationship between ADR and the risk of developing interval cancer (odds ratio, $0.52 ; 95 \%$ confidence interval: $0.39-0.69$ ) with a $3 \%$ reduction in the incidence of CRC and $5 \%$ mortality for each $1 \%$ increase in $\mathrm{ADR}^{(7)}$. Several authors have also shown that there is an inverse relationship between ADR and the occurrence of interval cancer ${ }^{(3)}$.

As already mentioned, American and European endoscopy societies have established minimum parameters for $\operatorname{ADR}^{(26,27)}$. However, it should not be considered a static target. The search for higher rates should be encouraged, respecting the peculiarities of each population and region. Abdul-Baki et al. monitored and evaluated endoscopists before and after the publication of the ADRs. They concluded that after reporting the rates, there was an increase from $4 \%$ to $17 \%$ in a subsequent ADR analysis ${ }^{(1)}$. More important than determining an acceptable ADR is to assess the progression of this rate over time. In this way, the influence of interventions aimed at improving rates can be better evaluated.

Sex and age are factors commonly identified as determinants of high $\mathrm{ADR}^{(22)}$. Both were analyzed in the present study. The association between ADR and gender, however, was not significant. Among the hypotheses raised to explain this fact, it is possible to highlight aspects of the distribution according to sex of the evaluated population sample. There was a predominance of female patients compared to male patients (66.3\% of females versus $33.7 \%$ of male patients), which differed from other available studies that reviewed this issue ${ }^{(17,31)}$. This observed discrepancy may be related to local sociocultural aspects, in which women have more guidelines for preventive examinations, for example, routine guidance for the prevention of $\mathrm{CRC}$, provided by gynecologists ${ }^{(12)}$. Another fact to be emphasized is that in the study city, there is a considerable predominance of women in relation to men (women between 50 and 74 years represent $55.6 \%$ of the total in this age group according to the 2010 Brazilian Demographic Census by the Brazilian Institute of Geography and Statistics - IBGE) ${ }^{(15)}$.

Also observed in the present study was an association between ADR and age group. The ADR of patients aged 50-59 was $22.4 \%$, and $31.9 \%$ for those aged $60-75$ years. The linear increase in the rate according to age group was also demonstrated by Diamond et al. ${ }^{(10)}$. In this study, ADR in men aged 50 to 55 years was approximately $25 \%$, whereas in the group of men aged 70 it was $39 \%$. These findings highlight the importance of considering a combination of demographic data in developing standards for ADR. A Polish study that evaluated 45,000 patients, found that ADR and patient age were the only predictors of interval cancer, highlighting the importance of these parameters as prognostic factors ${ }^{(18)}$.

The ADR was also associated with the use of chromoscopy techniques. In those patients in whom chromoscopy was performed, the ADR was $68.3 \%$, and $14.8 \%$ among those for whom it was not used. There was also a strong association of chromoscopy with the diagnosis of serrated lesions, which are difficult to diagnose.
Pohl et al. demonstrated that the use of chromoscopy, besides helping to find small polyps, may also aid in the detection of advanced adenomas ${ }^{(25)}$. The use of chromoscopy, therefore, may be a technical resource used to improve ADR.

These data, however, should be analyzed with caveats. Due to the retrospective nature of the study, it was not possible to evaluate the criteria for the use of chromoscopy. In some cases, it may have been used to improve diagnostic accuracy and ADR. However, it is known that there are situations where the chromoscopic features are only used after the diagnosis of a lesion with white light, to improve its macroscopic characterization. It was not possible to evaluate the ADR in relation to the type of chromoscopy - if only dyes such as methylene blue and indigo carmine were used, or if resources such as narrow band imaging (NBI) were available in the service.

The rate of polyp detection (PDR) has been proposed as an alternative to ADR as a quality indicator ${ }^{(26,27)}$. This refers to the proportion of colonoscopies with at least one polyp in relation to the total number of examinations performed. In the sample studied, the PDR was $35.1 \%$. Although it is related to ADR in several studies, this rate, however, may be imprecise. There is a risk of overestimating the value of a polyp that presents no risk of progression to neoplasia, such as hyperplastic polyps ${ }^{(26,27)}$.

This fact was observed when analyzing the adenoma/polyp relationship by regions of the colon examined. In the left colon, for example, the adenoma/polyp ratio was 1:1.9; while in the right colon this ratio was $1: 1.3$. The data from the present study allow us to infer that, for the left colon, PDR distances from ADR, overestimating the risk attributed to polyps. In relation to ADR, this may represent a parameter with less supporting evidence.

The study had some limitations. This was a retrospective study, with all the drawbacks inherent in this type of study. There was no way to test hypotheses and exclude potential confounders. Regarding the use of chromoscopy, it was not possible to measure the real impact of its use in the improvement of the ADR, only to observe a strong association between the variables analyzed.

The data cannot be generalized considering that it is a referral service, with endoscopists of great experience in the procedure. The number of procedures performed by these professionals might influence the ADR of the service. Comparing these data with services where there is training in colonoscopy may determine whether there is a difference in $\mathrm{ADR}^{(32)}$.

A quality indicator can be defined as the ratio between the best possible execution and the opportunities to achieve it ${ }^{(14)}$. Despite the differences between European and American populations and that of Brazil, it is concluded that the parameters proposed for assessing quality in colonoscopy by international consensus were reached in the West-Central Region of Brazil. The overall ADR of the service, and when stratified by sex, yielded values consistent with internationally established criteria. Age and the use of chromoscopy were directly related to the increase in ADR in the present study.

The need for further studies to consolidate colonoscopy quality parameters as well as ADR in Brazil and in the West-Central Region is essential, and assessing and improving ADR must be a continuing goal. In this way, it is possible to determine which factors influence the improvement or worsening of these rates or parameters, allow for better prevention and early diagnosis, and also better management of CRC with more precise interventions.

\section{Authors' contributions}

Cardoso DMM: study design, data analysis, preparation and revision of the manuscript. Botacin MAS and Mekdessi MA: study design, data collection and preparation of the manuscript. 
Cardoso DMM, Botacin MAS, Mekdessi MA. Qualidade em colonoscopia e taxa de deteç̧ão de adenoma no Centro-Oeste do Brasil. Arq Gastroenterol. 2017;54(4):315-20.

RESUMO - Contexto - O câncer colorretal é o terceiro câncer mais incidente em homens e o segundo em mulheres em todo o mundo. Peculiaridades de sua evolução permitem medidas de prevenção secundária através da colonoscopia, com alta capacidade diagnóstica e terapêutica. Nesse contexto os indicadores de qualidade se tornam importantes, dentre eles a taxa de detecção de adenomas (TDA). Objetivo - Avaliar a taxa de detecção de adenomas em uma população de médio risco submetida a colonoscopia, relacionando-a a indicadores sociodemográficos, técnicos e histopatológicos. Métodos - Trata-se de estudo descritivo, observacional e retrospectivo cujos dados foram coletados de registros e prontuários médicos de exames de colonoscopia com indicação de rastreamento ou prevenção do câncer colorretal no período de agosto a outubro de 2016. Resultados - Foram incluídos 436 laudos de exames para análise de dados. O sexo feminino representou 66,3\% com 289 pacientes contra 33,7\% de homens. Os pacientes entre 50 e 59 anos de idade foram $223(51,1 \%)$ e 213 entre 60 a 75 anos (48,9\%). Em 99 exames (22,7\%) foi feito uso de cromoscopia e 420 exames (96,3\%) tiveram preparo adequado. Cento e dezoito pacientes tiveram adenomas, resultando em uma TDA geral no serviço de 27,1\%. A TDA para homens foi de 30,6\% e 25,3\% para mulheres. Os pacientes entre 60 e 75 anos tiveram uma TDA significativamente maior ( $31,9 \%$, contra $22,4 \%$ dos mais jovens). Exames em que foi feito uso cromoscopia também apresentaram maior TDA. Conclusão - Os valores de TDA encontrados podem validar o uso de metas estabelecidas mundialmente para a população da região estudada e sua progressão temporal pode propor medidas para o aumento dessa taxa.

DESCRITORES - Adenomas. Câncer colorretal. Colonoscopia.

\section{REFERENCES}

1. Abdul-Baki H, Schoen RE, Dean K, Rose S, Leffler DA, Kuganeswaran E, et al. Public reporting of colonoscopy quality is associated with an increase in endoscopist adenoma detection rate. Gastrointest Endosc. 2015;82:676-82.

2. Institute of Medicine (US) Committee on Quality of Health Care in America To Err Is Human: Building a Safer Health System. The National Academies Press; 2000.

3. Baxter NN, Sutradhar R, Forbes SS, Paszat LF, Saskin R, Rabeneck L. Analysis of administrative data finds endoscopist quality measures associated with postcolonoscopy colorectal cancer. Gastroenterology. 2011;140:65-72.

4. Calderwood AH, Jacobson BC. Colonoscopy quality: metrics and implementation. Gastroenterol Clin North Am. 2013;42:599-618.

5. Calderwood AH, Thompson KD, Schroy PC 3rd, Lieberman DA, Jacobson BC Good is better than excellent: bowel preparation quality and adenoma detection rates. Gastrointest Endosc. 2015;81:691-9.

6. Cha JM. Would you recommend screening colonoscopy for the very elderly? Intest Res. 2014;12:275-80.

7. Corley DA, Jensen CD, Marks AR, Zhao WK, Lee JK, Doubeni CA, et al. Adenoma Detection Rate and Risk of Colorectal Cancer and Death. N Engl J Med. 2014;370:1298-306.

8. Corley DA, Jensen CD, Marks AR. Can we improve adenoma detection rates? A systematic review of intervention studies. Gastrointest Endosc. 2011;74:656-65.

9. Davila RE, Rajan E, Baron TH, Adler DG, Egan JV, Faigel DO, et al. ASGE guideline: colorectal cancer screening and surveillance. Gastrointest Endosc. 2006;63:546-57.

10. Diamond SJ, Enestvedt BK, Jiang Z, Holub JL, Gupta M, Lieberman DA, et al. Adenoma detection rate increases with each decade of life after 50 years of age. Gastrointest Endosc. 2011;74:135-40.

11. Fearon ER, Vogelstein B. A genetic model for colorectal tumorigenesis. Cell. 1990;61:759-67.

12. Federação Brasileira de Ginecologia e Obstetricia. Manual de Orientação em Climatério/ Consulta ginecológica: uma oportunidade para rastreamento do câncer colorretal. Femina. 2009;37(3).

13. Ferlay J, Soerjomataram I, Ervik M, Dikshit R, Eser S, Mathers C, et al. GLOBOCAN 2012 v1.0, Cancer Incidence and Mortality Worldwide: IARC CancerBase No. 11. Lyon, France: International Agency for Research on Cancer; 2013. [Internet]. [Accessed 2016 April 24]. Available from: http://globocan.iarc.f

14. Harewood GC, Sharma VK, de Garmo P. Impact of colonoscopy preparation quality on detection of suspected colonic neoplasia. Gastrointest Endosc. 2003;58:76-9.

15. Instituto Brasileiro de Geografia e Estatística Censo demográfico 2010. [Internet] [Accessed 18 April 2017]. Available from: http:www.ibge.gov.br

16. Instituto Nacional de Câncer. Rio de Janeiro; 1996-2016. [Internet]. [Accessed on 24 March 2016]. Available from: http://www.inca.gov.br/

17. Kahi CJ, Vemulapalli KC, Johnson CS, Rex DK. Improving measurement of the adenoma detection rate and adenoma per colonoscopy quality metric: the Indiana University experience. Gastrointest Endosc. 2014;79:448-54
18. Kaminski MF, Regula J, Kraszewska E, Polkowski M, Wojciechowska U, Didkowska J, et al. Quality indicators for colonoscopy and the risk of interval cancer. N Engl J Med. 2010;362:1795-803.

19. Kim HG. Is Elderly Age a Simple Predictive Factor for Inadequate Bowel Preparation before Colonoscopy? Gut Liver. 2016;10:489-90.

20. Lai EJ, Calderwood AH, Doros G, Fix OK, Jacobson BC. The Boston Bowe Preparation Scale: A valid and reliable instrument for colonoscopy-oriented research. Gastrointest Endosc. 2009;69(3 Pt 2):620-5.

21. Lieberman DA, Rex DK, Winawer SJ, Giardiello FM, Johnson DA, Levin TR Guidelines for colonoscopy surveillance after screening and polypectomy: a consensus update by the US Multi-Society Task Force on Colorectal Cancer. Gastroenterology. 2012;143:844-57.

22. Lieberman D, Mascarenhas R. Adenoma detection rate: in search of quality improvement, not just measurement. Gastrointest Endosc. 2015;82:683-85.

23. Menees SB, Kim HM, Elliott EE, Mickevicius JL, Graustein BB, Schoenfeld PS The impact of fair colonoscopy preparation on colonoscopy use and adenoma miss rates in patients undergoing outpatient colonoscopy. Gastrointest Endosc. 2013;78:510-6.

24. O'Connell JB, Maggard MA, Ko CY. Colon cancer survival rates with the new American Joint Committee on Cancer sixth edition staging. J Natl Cancer Inst. 2004;96:1420-5.

25. Pohl J, Schneider A, Vogell H, Mayer G, Kaiser G, Ell C. Pancolonic chromoendoscopy with indigo carmine versus standard colonoscopy for detection of neoplastic lesions: a randomised two-centre trial. Gut. 2011;60:485-90.

26. Rembacken B, Hassan C, Riemann JF, Chilton A, Rutter M, Dumonceau JM, et al. Quality in screening colonoscopy: position statement of the European Society of Gastrointestinal Endoscopy (ESGE). Endoscopy. 2012;44:957-68.

27. Rex DK, Schoenfeld OS, Cohen J, Pike IM, Adler DG, Fennerty MB, et al. Quality indicators for colonoscopy. Gastrointest Endosc. 2015;81:31-53.

28. Ries LAG, Melbert D, Krapcho M, Stinchcomb DG, Howlader N, Horner MJ, et al. SEER Cancer Statistics Review, 1975-2004. Bethesda, MD: National Cancer Institute 2007

29. Rosty C, Hewett DG, Brown IS, Leggett BA, Whitehall VLJ. Serrated polyps of the large intestine: current understanding of diagnosis, pathogenesis, and clinical management. J Gastroenterol. 2013;48:287-302.

30. Saha D, Roman C, Beauchamp D. New Strategies for Colorectal Cancer Prevention and Treatment. World J Sur. 2002;26:762-66.

31. Sanaka MR, Rai T, Navaneethan U, Gohel TD, Podugu A, Thota PN, et al Adenoma detection rate in high-risk patients differs from that in average-risk patients. Gastrointest Endosc. 2016;83:172-8

32. Solís-Muñoz P, Solís-Herruzo JA, Rodríguez-Muñoz S. Experience of the endoscopist increases detection rates of smaller size and higher histological grade polyps. J Gastroenterol Hepatol. 2014;29:1237-41

33. Wilkins T, LeClair B, Smolkin M, Davies K, Thomas A, Taylor ML, Strayer S. Screening colonoscopies by primary care physicians: a meta-analysis. Ann Fam Med. 2009;7:56-62. 